which is particularly useful not only to foreigners but to all who have to write prescriptions to be dispensed abroad.

This volume is essentially a practical textbook rather than a book of reference as lists of references are purposely omitted. Within its covers is contained the essentials of dermatology presented in an attractive form.

At the price of $20 /-$ the book is excellent value.

\section{THE PHYSIOLOGICAL BASIS OF MEDICAL PRACTICE.}

By Charles Herbert Best, M.D., \&c., and Norman Burke TAYloR, M.D., \&c. Baillière Tindall \& Cox. 1937. Price 45/-.

In their preface the authors dilate on the importance of the physiological approach to disease. While we will not debate with them the suitability of the title of their joint work nor quarrel with them over the amount of the debt which the physician owes to the physiologist, we may be permitted to point out that the physiologist of to-day does not interest himself only in the normal but just as much in the pathological. Indeed it was only when he commenced to pay attention to the latter, and by using the abnormal behaviour of the body as the guide to the discovery of the function of an organ, that he has made the rapid strides in his knowledge, so marked during the present century, and has contributed so much to our understanding of disease processes. This, of course, is particularly true so far as the chemical processes of the body are concerned. Thus we would rather see the more general term-biochemistry-employed than either of the frequently applied synonyms-physiological or pathological chemistry. We have always felt that the value of a medical training to the physiologist or biochemist is proof of this point of view, and if we have any serious criticism to make of the above volume it is that it reveals too little first-hand acquaintance with disease. Otherwise, one would not find splenectomy recommended for Gaucher's disease or the explanation of the value of the same operation in acholuric jaundice that it brought about a diminution in the fragility of the red cells.
However, whatever the title, this is a book which we can recommend with the greatest of confidence, for by its study the reader will acquire not only an increased interest in the investigation of disease but at the same time the greatest help in its understanding, and hence an intelligent application of therapeutic measures. It is, indeed, a perfect mine of information regarding our present-day knowledge of the blood and circulation, respiration, renal function, digestion and nutrition, and endocrinology. Many details regarding experimental observations are supplied and the significance of their application to diagnosis and treatment is fully discussed. There are numerous illustrative diagrams and photographs, although not a few of the latter leave much to be desired. It looks as if in some instances they have been reproduced from already printed half-tone blocks and not from original photographs. One also regrets that the American method of spelling has been adopted by Canadian authors.

\section{THE ENDOCRINES IN OBSTETRICS \& GYN\#COLOGY} By Raphael KurzroK, Ph.D., M.D. Balliére, Tindall \& Cox, London, 1937, pp. xvi-488. 178 illustrations, price 34/-.

This book, which emanates from the departments of Biochemistry and of Obstetrics and Gynæcology of the Columbia University Medical Centre, is a valuable review of recent work in endocrine physiology, and contains the results of clinical observations during 10 years in the Medical Centre, and at the Bronx and Morrisania Hospitals, New York.

Most books on the Female Sex Hormones deal only or mainly with the theoretical aspects of the subject, and as the authors are not themselves engaged in clinical work, ignore their clinical applications. In this book, however, the clinical aspects are dealt with very fully and therein lies, in our opinion, its great merit for the postgraduate student.

The opening chapter contains a short but adequate account of the history of the subject. Then follow well illustrated chapters on the physiology and histology of the uterus and glands of internal secretion, including pituitary, thyroid and pancreas, 